\title{
The Influence of Reinforcement Ratio to the Mechanical Behavior of Reinforced Concrete Column
}

\author{
Hong-Yu DENG ${ }^{1, a^{*}}$, Bai-Tao SUN ${ }^{2, b}$ \\ ${ }^{1}$ College of Space Technology and Civil Engineering Harbin Engineering University, Harbin 150001, \\ China \\ ${ }^{2}$ Earthquake Administration, Key Laboratory of Earthquake Engineering and Engineering Vibration \\ of China Earthquake Administration, Harbin 150080, China \\ adengblue@163.com, bsunbt@iem.cn \\ ${ }^{*}$ Corresponding author
}

Keywords: Reinforcement Ratio, Stirrup Ratio, Reinforced Concrete Column, Pseudo-Static Test.

\begin{abstract}
Steel and concrete were the most important building materials, reinforced concrete was widely used in building structures. For the study of the influence of steel bar content in reinforced concrete columns, three specimens were designed for pseudo static test. The test shows that: the stirrup ratio does not significantly affect the bearing capacity and stiffness degradation of column, but when the stirrup ratio is too low will reduce the ductility and energy dissipation capacity of column. To improve the ratio of longitudinal reinforcement can significantly improve the bearing capacity of the column, but will decrease the energy dissipation and ductility, stiffness degradation becomes more serious.
\end{abstract}

\section{Introduction}

In building structure, reinforced concrete structure was a form of the most widely used, steel and concrete could work together was determined by the material properties of its own. First of all, steel and concrete had approximately the same linear expansion coefficient, and will not produce excessive stress due to different environment. Secondly, there was good adhesion between steel and concrete, reinforced rib could improve the mechanical engagement between concrete and steel. The stirrup was used to meet the shear strength of the inclined section, and connected reinforcement and compressive region concrete. Therefore, reinforcement ratio had an important effect on mechanical properties of the mechanical behavior of reinforced concrete column.

\section{Specimen Design and Test Methods}

Specimen Design. Three reinforced concrete frame column specimens were designed. The stirrup ratio was different between $\mathrm{Z} 1$ and $\mathrm{Z} 2$, while the stirrup ratio was different between $\mathrm{Z} 1$ and $\mathrm{Z} 3$.The specific parameters were shown in tab.1.

Tab.1 The design parameters of reinforced concrete frame column

\begin{tabular}{|c|c|c|c|c|}
\hline No. & $\begin{array}{c}\text { axial compression } \\
\text { ratio }\end{array}$ & stirrup ratio & $\begin{array}{c}\text { the ratio of longitudinal } \\
\text { reinforcement }\end{array}$ & $\begin{array}{c}\text { shear span } \\
\text { ratio }\end{array}$ \\
\hline $\mathrm{Z} 1$ & 0.9 & $\Phi 8 @ 85 / 150(4)(1.8 \%)$ & $12 \Phi 14(2.05 \%)$ & 2.92 \\
\hline $\mathrm{Z} 2$ & 0.9 & $\Phi 6 @ 150(2)(0.29 \%)$ & $12 \Phi 14(2.05 \%)$ & 2.92 \\
\hline $\mathrm{Z} 3$ & 0.9 & $\Phi 8 @ 85 / 150(4)(1.8 \%)$ & $12 \Phi 20(4.19 \%)$ & 2.92 \\
\hline
\end{tabular}

Material Characteristic Test and Results. Steel tensile strength was tested by five 6 , two 8 , four 14, two 22, the average results were shown in Tab.2. The grade of concrete strength was C30, three concrete test cube by $150 \mathrm{~mm} \times 150 \mathrm{~mm} \times 150 \mathrm{~mm}$ in one-time-concreting were taken through axial compressive strength test, the results were shown in Tab.3. 
Pseudo-static Test. The test method was the quasi-static test ${ }^{[1]}$, by applying multiple reciprocating cyclic loading on the component, the structure repeated the process of loading and unloading in the pros and cons direction, to simulate the deformation characteristics and force characteristics of the structure in reciprocating vibration during earthquake. The purpose was to establish the restoring force characteristics of structure under earthquake, and determine the calculation model of restoring force of structural members, which could judge the seismic performance of structure in the strength, deformation and energy dissipation.

Tab.2 Material characteristic results of steel bar

\begin{tabular}{|c|c|c|c|c|}
\hline Steel bar & $\begin{array}{c}\text { Diamete } \\
\mathrm{r}[\mathrm{mm}]\end{array}$ & $\begin{array}{c}\text { Yield } \\
\text { strength[MPa] }\end{array}$ & $\begin{array}{c}\text { Ultimate } \\
\text { strength [MPa] }\end{array}$ & $\begin{array}{c}\text { Yield } \\
\text { strain }\end{array}$ \\
\hline Stirrup (HPB235) & 6 & 447 & 638 & 0.002235 \\
\hline Stirrup (HPB235) & 8 & 417.5 & 527.5 & 0.002088 \\
\hline Longitudinal reinforcement (HRB335) & 14 & 493.8 & 657.8 & 0.002469 \\
\hline Longitudinal reinforcement (HRB335) & 20 & 480 & 597.5 & 0.0024 \\
\hline
\end{tabular}

Tab.3 Material characteristic results of concrete test cube

\begin{tabular}{|c|c|}
\hline No. & Axial compressive strength $[\mathrm{MPa}]$ \\
\hline 1 & 47.93 \\
\hline 2 & 46.01 \\
\hline 3 & 45.73 \\
\hline Average & 46.5 \\
\hline
\end{tabular}

Loading Equipment. The reinforced concrete column end was anchored and horizontal cyclic loading was applied on the top. A vertical concentrated load was applicated on the top of the column, though and upper roller device between the hoisting jack and reaction beam to ensure the top of the column could produce free horizontal displacement[2]. The test equipment was shown in Fig.1. The horizontal load is loaded by the method of deformation control: When the specimen cracked, according to multiple cracking displacement to load step by step, two cycles per level, until the first cycle load of the structure was lower than $85 \%$ maximum load, and it was considered that structure had already destroyed. The test loading program was shown in Fig. 2.

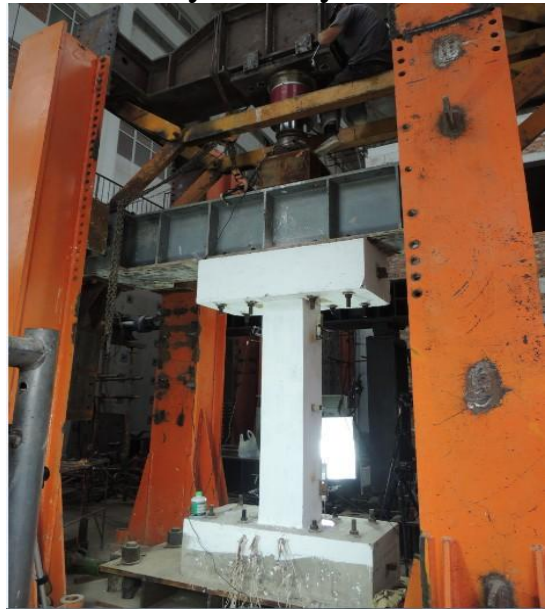

Fig.1 Test equipment

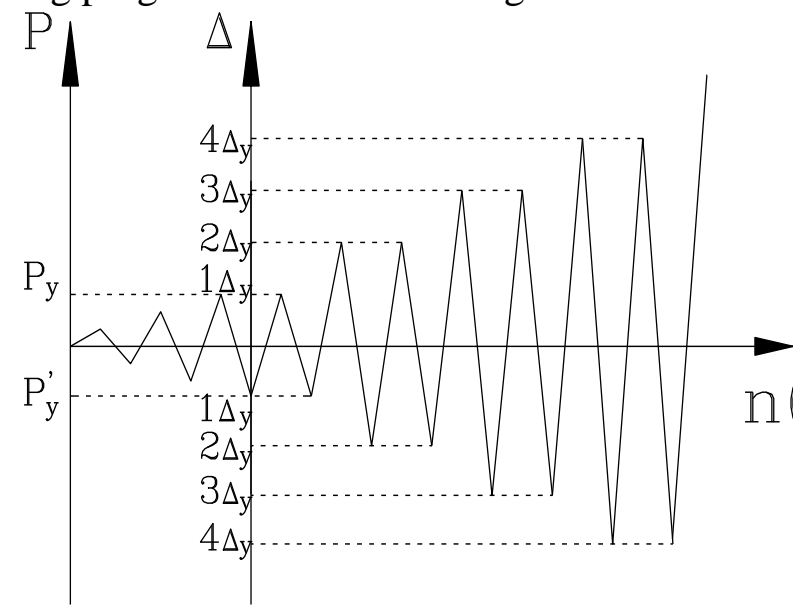

Fig. 2 Test loading program

Experimental Phenomena. Specimen Z1 was taken as an example to explain the phenomenon in the process of test. When $2 \Delta$, mortar and concrete were peeled on the upper column at the height of 1-1.5 section, vertical cracks appeared, the compression zone of mortar layer appeared obvious signs of crushing. When $5 \Delta$, the crushing of concrete significantly increased, cracking phenomenon 
increased slightly, the inclined crack appeared. When $12 \Delta$, spalling phenomenon intensified, crushing area depth increased to $8-10 \mathrm{~cm}$. When $15 \Delta$, longitudinal reinforcement yielded, stirrup exposured, the specimen failured at the end of test (Fig. 3).
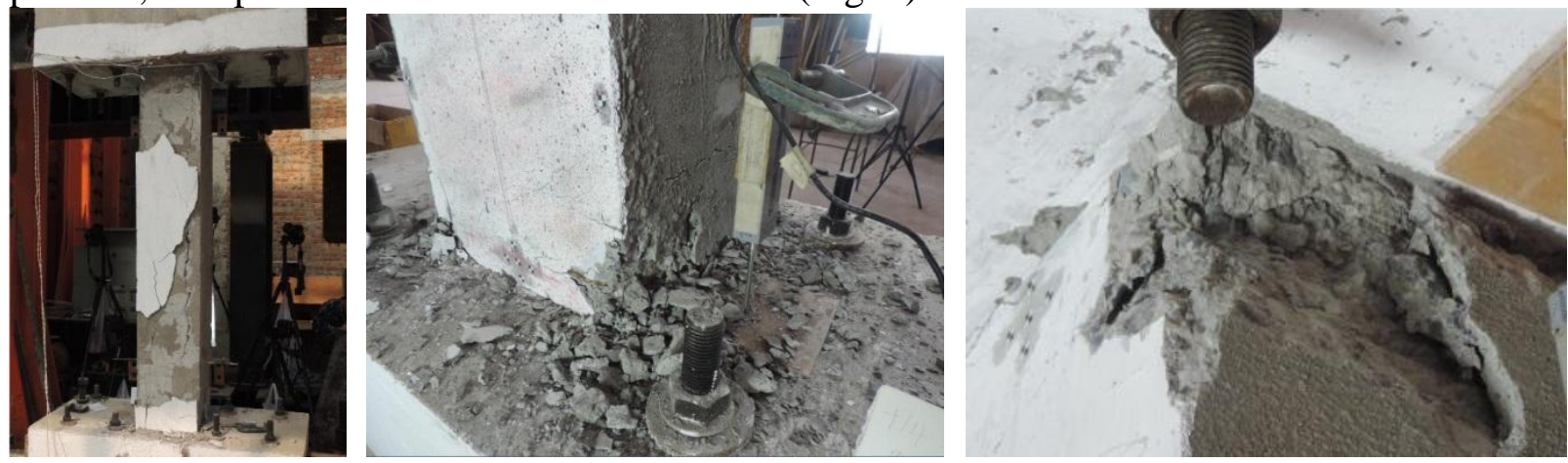

Fig.3 Failure situation of Z1

\section{The Results of Test and Analysis}

Load- hysteretic Curve. Load-hysteretic curve ${ }^{[3]}$ of the test results as shown in Fig. $4 . \mathrm{Z} 1$ and $\mathrm{Z} 2$ had different stirrup ratio, and there was little difference bearing capacity between the Z1 and Z2 from the hysteresis curve. But the hysteretic curve of Z2 was not full, ductility coefficient and energy dissipation ability was poor. When overcome limit load, the bearing capacity decreased rapidly which showed a brittle failure. Z1 and Z3 had different longitudinal reinforcement rate. As the longitudinal reinforcement ratio of $\mathrm{Z} 3$ was higher, the bearing capacity had been improved, but due to not enough bar anchorage length on mid-span, an anchor destroy occurred, leaded to hysteresis curve decreased rapidly soon after exceeding the maximum load bearing capacity. The hysteretic area became smaller, and the limit displacement decreased, energy dissipation and ductility were poor by comparing with Z1.

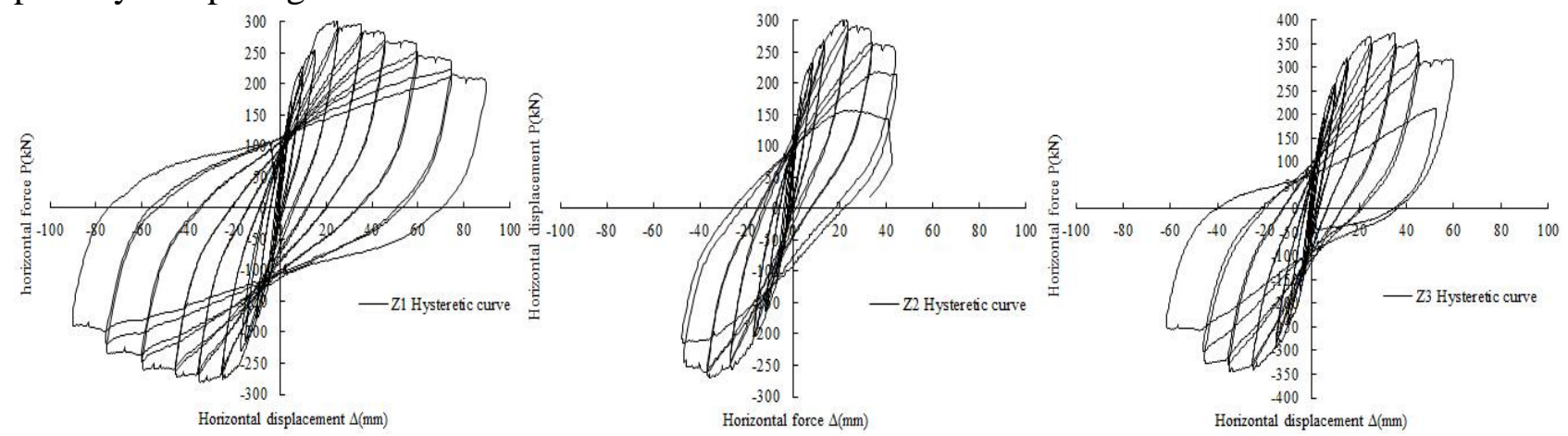

(a) Z1

(b) $\mathrm{Z} 2$

(c) Z3

Fig.4 Load-hysteretic curve of specimens

Energy Dissipation. For a certain hysteresis curve, the area enclosed by the rising curve segment and coordinate at the time of loading represents the energy that structure absorbed. The area which was enclosed by the rising curve segment and coordinate at the time of loading represented the energy that structure released. Such a hysteresis loop area represented the energy that dissipated by members during the time of loading (Fig. 5). The evaluation index for energy dissipation in general was the equivalent viscous damping coefficient ${ }^{[4]}$ he, the calculation formula was as Eq. 1 . The positions of A-F points were shown in Fig. 5. The values of he of specimen Z1, Z2 and Z3 according to the calculation Eq. 1 were shown in Fig. 6 and Fig. 7. Comparing Z1 and Z2, the equivalent viscous damping coefficient had the same general trend. That illustrated the stirrup ratio had little effect on the energy dissipation capacity. Comparing Z1 and Z3, Z1 was slightly higher than Z3. Analysis of the reasons, Z1 had lower reinforcement ratio and reinforced yielded earlier into plastic stage which increased energy consumption. The energy dissipation capacity was stronger than that of Z3. 


$$
h_{e}=\frac{1}{2 \pi} \frac{S_{(A B C+C D A)}}{S_{(O B E+O D F)}}
$$

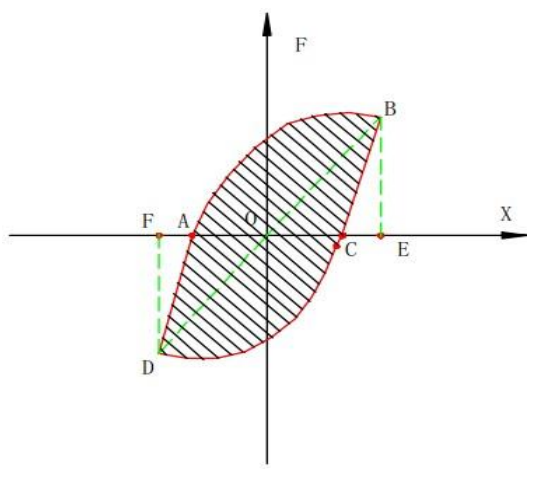

Fig.5 Load- hysteretic curve

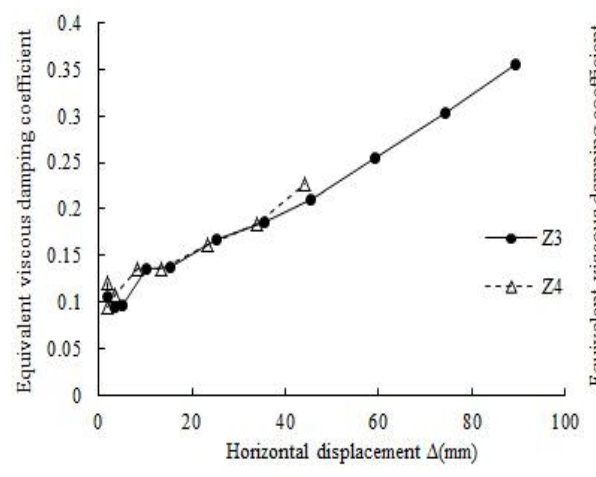

Fig. 6 he of $\mathrm{Z} 1$ and $\mathrm{Z} 2$

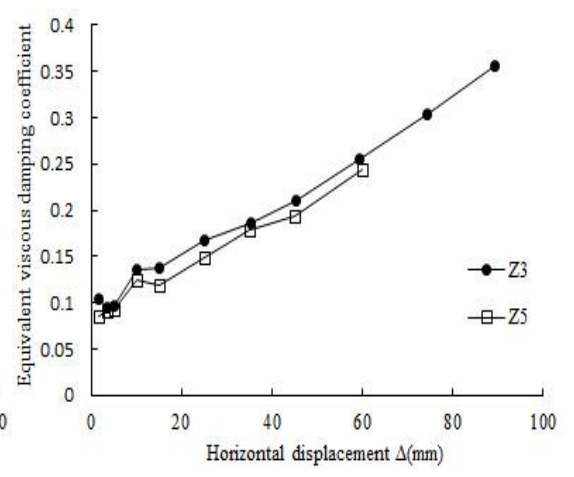

Fig.7 he of $\mathrm{Z} 1$ and $\mathrm{Z} 2$

Stiffness Degradation. In this paper, using the deformation of the ring stiffness to measure the stiffness degradation of specimens, the calculation formula was as Eq. $2 . F_{j}^{i}$ was the value of the load refers to the peak displacement of i cycles in a location shift control value. $U_{j}^{i}$ was the value of the displacement refers to the peak displacement of i cycles in a location shift control value. $n$ was the cycle number. The ring stiffness calculation results of $\mathrm{Z} 1$ to $\mathrm{Z3}$ according to the Eq. 2 were shown in Fig. 8 and Fig. 9. Comparison of Z1 and Z2, the Z1 stiffness with larger stirrup ratio increased slightly, the ring stiffness curves were basically consistent. That illustrated the stirrup ratio had little effect on the stiffness degradation. Comparison of Z1 and Z3, the stiffness of Z3 with larger longitudinal reinforcement ratio was obviously higher than that of $\mathrm{Z} 1$, but the circular curve declined more rapidly. That illustrated the bigger the longitudinal reinforcement ratio of the specimen stiffness degradation more quickly.

$$
K_{i}=\sum_{i=1}^{n} F_{j}^{i} / \sum_{i=1}^{n} U_{j}^{i}
$$

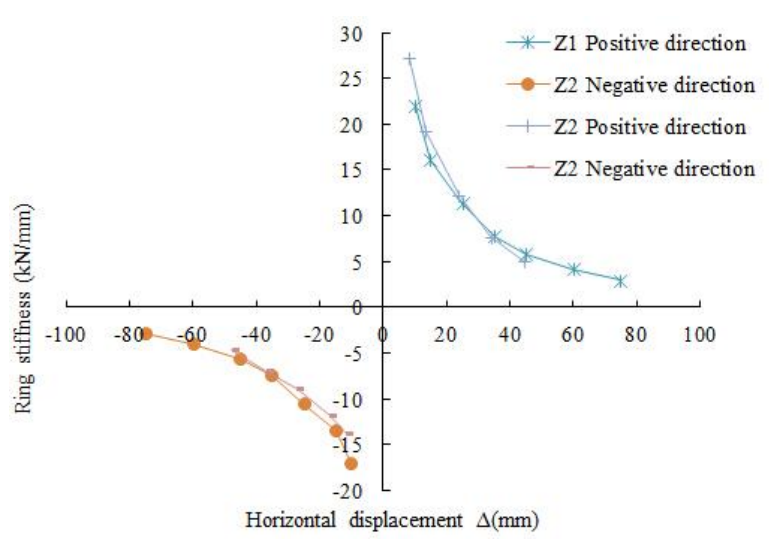

Fig.8 Ring stiffness of Z1 and Z2

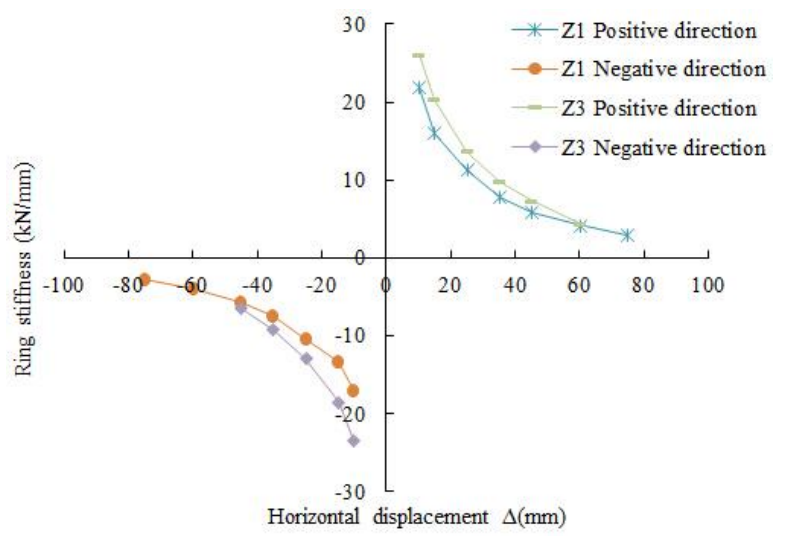

Fig.9 Ring stiffness of Z1 and Z3

\section{Conclusions}

Stirrups stirrup ratio has great influence on the mechanical behavior of reinforced concrete frame columns. When the stirrup ratio is low, the energy dissipation capacity and ductility decrease, and it is easy to brittle failure. But it has little effect on maximum bearing capacity of column and stiffness degradation. 
Longitudinal reinforcement ratio has great influence on the mechanical behavior of reinforced concrete frame columns. When the reinforcement ratio is larger, the maximum bearing capacity, energy dissipation and ductility of column decrease, and has much faster stiffness degradation.

The stirrup ratio is the main factor on affecting the shear bearing capacity of concrete, reinforcement ratio can control the failure mode of normal section of structural component. The sizes of the two should be appropriate, concrete and steel are just to play their respective performance to limit the damage, to avoid the occurrence of brittle failure.

\section{Acknowledgment}

This research is supported by major research plan of national natural science foundation of china (91315301-10), the special research in Chinese seismological industry (201508026) and special research in Chinese seismological industry (201508010-06).

\section{References}

[1]L. X. Zhang: Specification of Testing Methods for Earthquake Resistant Building, edtied by China Architecture \& Building Press, Beijing 2001, pp. 9-16.

[2]Z. Jun. Study on Energy-consumption Performance of Different Yield Points Reinforced Concrete Column, Yangzhou University, China Yangzhou, 2011.

[3]H. Jun, X. L. Hua, D. S. Bin. Pseudo-static Test On Side Joint Of Concrete Column-steel Beam, Journal of Earthquake Engineering and Engineering Vibration, Vol. 28(2008), p. 59-63.

[4]L. H. Han, J. T. You, Y. F. Yang, Z. Tao, Behavior Of Concrete-Filled Steel Rectangular Hollow Sectional Columns Subjected To Cyclic Loading, China Civil Engineering Journal, Vol. 37(2004), p. 11-22. 